Article

\title{
The Spatial and Temporal Evolution of Logistics Enterprises in the Yangtze River Delta
}

\author{
Meiling $\mathrm{He}^{1, * \mathbb{C}}$, Lei Zeng ${ }^{1}$, Xiaohui $\mathrm{Wu}^{1}$ and Jianqiang Luo ${ }^{2}$ \\ 1 School of Automobile and Traffic Engineering, Jiangsu University, Zhenjiang 212013, China; \\ zenglei4117@163.com (L.Z.); wuxiaohui@ujs.edu.cn (X.W.) \\ 2 School of Management, Jiangsu University, Zhenjiang 212013, China; luojianqiang@ujs.edu.cn \\ * Correspondence: hemeiling@ujs.edu.cn
}

Received: 19 August 2019; Accepted: 24 September 2019; Published: 26 September 2019

check for updates

\begin{abstract}
With the deepening of economic globalization, the global freight volume has been constantly on the rise; and urban logistics space is gradually changing as well. Reorganization of urban logistics space is closely related to sustainable development. It has great influence on rational distribution of social resources, improvement of urban ecological environment, and balance of urban economic structure. This paper takes A-level logistics enterprises in the Yangtze River Delta as the object of study, aiming at revealing the spatial and temporal evolution of A-level logistics enterprises in Shanghai and Yangtze River Delta in 2005-2015 from the metropolitan and regional levels, respectively, and at providing reference for the rational planning of logistics space. The analysis result shows that the logistics sprawl occurs in various degrees in Shanghai and the Yangtze River Delta, and in the process of logistics enterprises moving from urban centers to the suburbs, the characteristics of logistics enterprises cluster keep emerging and gradually form a specific status. Then, we analyze the reasons underlying the formation of the spatial and temporal distribution pattern of logistics enterprises in light of relevant policies, geography and the sustainable development of economy, thus providing relevant suggestions for the government and logistics enterprises.
\end{abstract}

Keywords: logistics enterprises; logistics space; logistics sprawl; logistics cluster; spatial-temporal evolution

\section{Introduction}

With the development of economic globalization, modern logistics industry has grown into a new type of compound industry with strong permeability that spans across different industries, departments, and regions, having gradually become China's third source of profits [1,2]. As a new engine to propel the economic growth, logistics plays a key role in breaking the time and space restrictions between the origin and destination [3]. Industrial space is the economic phenomenon where a certain industry combines spatial distribution with industry in a country or region. Logistics space is one of the industrial spaces that entail the projection of urban logistics activities (professional market, logistics enterprise, logistics node, logistics infrastructure) in geospatial space [4]. The research on logistics space mainly focuses on the spatial and temporal analysis of regional logistics, studies on the economic organization, spatial structure reconstruction, and internal mechanism of modern logistics, and further exploration into the systematic planning and optimization of the overall spatial structure of regional logistics industry [5]. At the same time, with the continuous expansion of urban centers, many logistics enterprises move out and cluster in space, which not only greatly reduces the pressure of urban traffic, but also effectively reduces the impact of noise and pollution [6]. Therefore, the development of logistics space becomes ever more important for the sustainable development of logistics in terms of environmental, social, and economic efficiency. 
In recent years, the research on regional logistics space has caused widespread concern in academic circles. Many scholars have studied the regional logistics space, especially its two major phenomena: Sprawl and cluster. In studying the logistics space, scholars have found that logistics facilities are gradually moving from urban centers to suburbs. A spatial dynamic study of Tokyo's logistics facilities found that logistics facilities moved outwards by $26 \%$ in 10 years [7]. In addition, other metropolitan areas in the world such as Gothenburg, Los Angeles, California, Seattle, Paris, and Toronto have also witnessed the phenomenon of logistics sprawl [8-11]. In the process of studying the phenomenon of logistics sprawl, scholars have also revealed that logistics facilities are forming the phenomenon of cluster in geographical space, and have a positive impact on regional economic development. According to the data of large-scale freight survey in the Greater Tokyo Metropolitan Area, the integration of logistics facilities has improved the transportation efficiency of freight by 4\% [7]. A study on the carbon emission of prefecture-level cities in China also proved that industrial cluster can improve not only the allocation efficiency of energy and resources through price and competition mechanism, but also the environment and sustainable social development through knowledge spillover, technological innovation and resource sharing [12]. In the process of the sprawl of logistics enterprises, those with similar types and mutually beneficial functions begin to form a cluster effect in geographic space due to the Industrial Synergy Effect, so as to share business behavior and specific resources and then improve the competitiveness of logistics enterprises. This phenomenon is called the integration of logistics space. The integration of logistics space will promote the reorganization of urban space, and then affect the spatial structure of the city, which will have a tremendous impact on the rational distribution of social resources, the improvement of urban ecological environment and the balance of urban economic structure. Therefore, the reorganization of logistics space is closely related to the sustainable development of society. A reasonable study of logistics space is conducive to promoting the sustainable development of society in the process of urbanization.

As one of the six major urban clusters in the world and the largest economic area with the strongest comprehensive strength in China, the Yangtze River Delta is gradually growing into a global logistics hub [13]. Since the reform and opening up, the economic development policy of China has been giving priority to the eastern region, thus promoting the development of the central and western regions. As the core area of the eastern region, the Yangtze River Delta has always been the leader of China's economy. The analysis of the spatial and temporal evolution of the logistics space in the Yangtze River Delta is conducive not only to enriching the logistics geography studies on the logistics space in metropolitan areas, but also to providing reference for related logistics space problems faced by other countries in the process of sustainable social development and urbanization. It is of great guiding significance to the rational allocation of urban logistics resources and the coordination of logistics and economic development, provides a new perspective for the government and enterprise to plan social sustainable development, and further promotes the rapid development of regional economy and logistics industry. In China, most logistics facilities belong to private property for enterprises. Due to the protective principle, it is very difficult to obtain the location of specific logistics facilities. Therefore, unlike studies on logistics facilities in developed capitalist countries such as Europe and the United States, the study of logistics space in China mostly focuses on logistics enterprises.

In addition to the Introduction in Section 1, the paper consists of the following contents: Section 2 is a literature review on the spatial sprawl and cluster of logistics space in recent years; in Section 3, the area and data of the analysis are presented; in Section 4, we analyze the spatial and temporal evolution of logistics enterprises at the metropolitan level in Shanghai in 10 years; in Section 5, we analyze the spatial and temporal evolution of logistics enterprises at the regional level in the Yangtze River Delta in 10 years; Section 6 includes a discussion on some key changes underlying the spatial and temporal distribution pattern of logistics enterprises in the Yangtze River Delta from the perspective of sustainable development as well as relevant suggestions for the government and logistics enterprises; in the conclusion part, the research of this paper is summarized. 


\section{Literature Review}

\subsection{Logistics Sprawl: Definitions and Development}

With the deepening of economic globalization, the increasing demand for logistics has put forward higher requirements for the transformation and upgrading of modern logistics industry. At the same time, along with the reorganization of urban space, urban logistics space also faces the inevitability of reorganization [14]. One of the most significant phenomena in many metropolises in the past decade is that many logistics facilities and warehousing centers are gradually shifting from urban centers to suburbs; researchers have called this phenomenon logistics sprawl [15]. Therefore, how to align the reorganization of urban logistics space with the reorganization of urban space, that is to explore the changes and trends of urban logistics space, has become research highlights in recent years, which has aroused the interest of scientific planning researchers of many cities in the world.

The research on the logistics space first starts with the warehouse. Bowen studied the geographical location changes of American warehouses during 1998-2005, by comparing the number of warehouses with the accessibility of county-level traffic and highways and exploring the degree of correlation between the two indexes, which is also the earliest study on the spatial connections of logistics space from a geographical perspective [16]. After that, scholars all over the world began to study the spatial reorganization of logistics facilities from the perspective of geography. For instance, Dablanc were the first scholars to study the phenomenon of logistics sprawl, and by studying the geographic changes of Paris express industry from 1974 to 2008, they found that parcels and express companies shift from Paris city center to suburbs, and this degree of dispersion is much higher than that of employment and households [15].

Then, after decades of development, existing studies use data from different metropolitan areas to verify the occurrence of logistics sprawl. Different literatures describe various methods to measure the dimension of spatial reorganization of logistics space. However, the most direct and effective method used by researchers is to measure the mean distance between logistics facilities and urban centers. For instance, Heitz took the spatial distribution of freight and logistics facilities in the Paris area from 2000 to 2012 as the research object, and evaluated the spread of logistics facilities by selecting the standard deviation ellipse and the mean distance of the logistics facilities from the center of gravity. The results showed that the mean distance of the logistics facilities from the center of gravity increased by $0.5 \mathrm{KM}$ in 12 years, which validated the occurrence of the proliferation of logistics facilities with statistical data [10]. Additionally from this point of view, Dablanc studied warehouses in Atlanta and Los Angeles from 1998 to 2008, and found that their mean distances increased by $4.2 \mathrm{~km}$ and $6.1 \mathrm{KM}$, respectively in 10 years [9,17]. Heitz studied the logistics facilities in Gothenburg from 2002 to 2014 and found that the mean distance increased by $4.2 \mathrm{~km}$ [8]. Sakai studied the logistics facilities in Tokyo from 2003 to 2013, and found that the mean distance increased by $6.6 \mathrm{~km}$ [7]. These studies all confirmed at the data level that the phenomenon of outward sprawl of logistics facilities is occurring in metropolitan areas all over the world.

In fact, no matter what kind of research methods is employed, the study of logistics space needs a large number of accurate data. However, different countries and regions in the world have different definitions of logistics facilities, and the degree of data accessibility varies greatly. Therefore, there are some differences in data selection and acquisition between different regions. Generally speaking, National Statistical Yearbook (The statistical yearbook is generally subdivided by zip-code for analysis) and sample survey data of logistics enterprises based on network resources are the most commonly used data sources. For instance, zip-code, and county-level data have been used in quite a few studies, especially in North America $[11,18,19]$. In another data type, based on Tencent's online map platform, Li collected 4396 logistics interest points in Beijing and Jiang collected the data of A-level logistics enterprises from 2005 to 2015 in Zhejiang Province, China, to analyze the evolution of logistics space in corresponding regions [20,21]. Comparatively speaking, the data of the National Statistical Yearbook are easier to obtain and more complete, but the accuracy is not high, and it is suitable 
for more macro-analysis. Though the sample survey data of logistics enterprises are more accurate, the data acquisition is difficult and incomplete, so it is suitable for deep-seated and small-scale logistics space research.

In the literature review of logistics space, scholars analyze and collect the phenomena of logistics sprawl and cluster in different regions of the world, and systematically analyze and summarize the relationship between logistics space change and related factors. For example, He systematically summarized and compared the phenomenon of sprawl and cluster of logistics facilities around the world, exploring the reasons for the sprawl and cluster of logistics facilities from the perspective of sustainable development through a comparison of research areas, methods, and contents [4]. Aljohani detailed the impact of logistics sprawl on urban environment and logistics industry in the literature, elaborated the reasons for the sprawl of logistics from the aspects of environment and sustainable development, and pointed out the positive and negative impacts of logistics sprawl on social activities [22].

\subsection{Logistics Cluster: Definitions and Development}

In the process of studying the phenomenon of logistics sprawl, researchers have also found another important and interesting phenomenon: Logistics cluster. For the definition of logistics cluster, there is no comparatively unified view in academic circles at present. Rivera defined logistics cluster as the concentration of third party logistics (3PL-S), transporters, warehousing suppliers, and freight forwarders providing logistics services [23]. In fact, different from the phenomenon of logistics sprawl; logistics cluster is not only a simple geographical concentration of logistics facilities, but also a concentration of resources such as industry, technology, talent, capital, information, etc. [24].

Initially, the study of logistics cluster was usually based on the phenomenon of logistics sprawl. For example, by comparing the changes of logistics facilities in Paris in 2002 and 2012, Heitz found that while logistics facilities are expanding outward, they also form a certain geographic cluster phenomenon, and he also explored the centripetal force that causes the phenomenon of logistics cluster [25]. Similarly, Cao's research on Suzhou's logistics space in China, Alho's research on Portuguese logistics space, and Sakai's Research on Tokyo logistics space, all found that the phenomenon of logistics cluster simultaneously occurs with logistics sprawl [26-28].

With the continuous maturity of logistics geography, the follow-up research began to explore the phenomenon of logistics cluster from the perspectives of economics, logistics, urban planning, and geography. Kumar used the methods of spatial clustering and econometrics to demonstrate that logistics cluster not only occurs in metropolitan areas of the United States, but also exists in non-metropolitan areas, and the cluster intensity is closely related to transportation infrastructure [29]. $\mathrm{Xu}$ evaluated the impact of the cluster effect of logistics industry on the economy in the Yangtze River Delta from the perspective of spatial economics, and found that logistics cluster has become an important engine of regional economic growth in recent years [30]. Nowadays, more and more scholars pay attention to the phenomenon of logistics cluster, which has become one of the important links in analyzing the spatial and temporal evolution of regional logistics.

In the past decades, many empirical studies on logistics space in developed capitalist countries and regions such as Europe and the United States have confirmed the occurrence of logistics sprawl and cluster. Due to the fundamental differences in political systems between socialist countries and capitalist countries, there are great differences in economic systems. Are there logistics sprawl and cluster in socialist countries? This is a very interesting research issue worth exploring further. As the fastest developing and most influential socialist country in the world, it is of great significance for China to study its logistics space. In the theoretical sense, it can bring a new perspective to logistics geography and enrich the current academic research on logistics space. In the practical sense, it can provide reference for other countries, promote the integration of logistics space and urban space, and promote the sustainable development of society. 


\section{Study Area and Data}

In the research of logistics sprawl and cluster, due to the difference of regional environment and the different definitions of relevant data, the choice of regions and data is the fundamental difference of each study. This section first briefly introduces the regional environment of the Yangtze River Delta and Shanghai, and then introduces the definition and sources of relevant data.

\subsection{Study Area}

In the empirical analysis, we selected the Yangtze River Delta, the largest economic circle in China, and Shanghai, which is located in the core of the Yangtze River Delta, as the research objects. The spatial and temporal evolution of logistics space from 2005 to 2015 is analyzed from the regional and metropolitan levels, respectively. Figure 1 is the geographical location map of Yangtze River Delta.

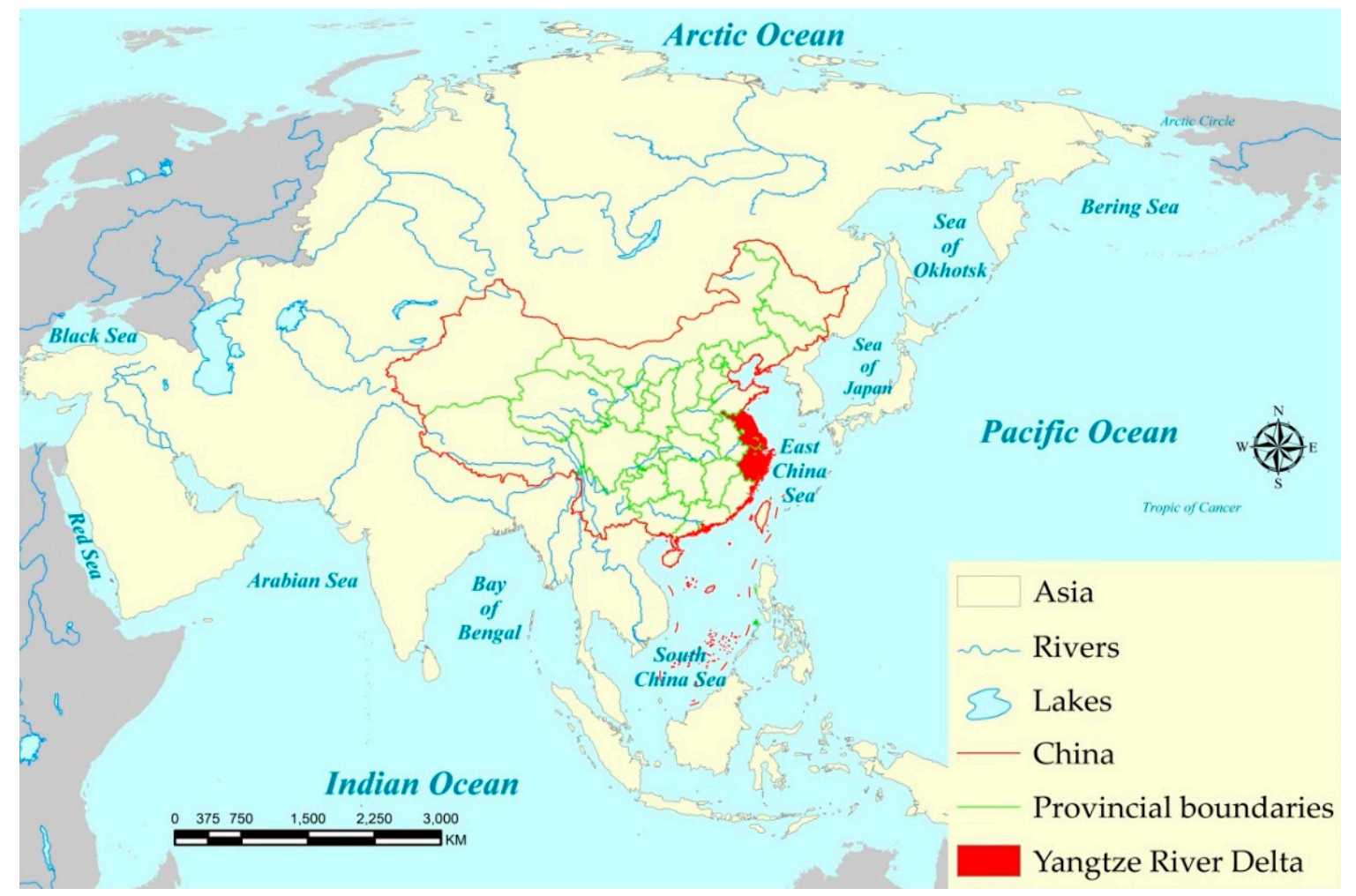

Figure 1. The geographical location of the Yangtze River Delta.

The Yangtze River Delta: The Yangtze River Delta is an alluvial plain before the Yangtze River flows into the sea, situated on the eastern coast of the mainland of China. According to the Yangtze River Delta Regional Planning approved by the State Council in 2010, the Yangtze River Delta includes Shanghai, Jiangsu, and Zhejiang provinces. The regional area has a land area of 21.07 million square kilometers and a population of 160 million in 2018. As the largest economic zone in China, the Yangtze River Delta has the most developed tertiary industry and transportation network in China, which greatly stimulates the development of private economy and service industry, so the quantity and quality of its enterprises rank first in China. In terms of strategic development, the Yangtze River Delta has been positioned by the Chinese government as an important international gateway in the Asia-Pacific region and an important advanced manufacturing base in the world. It is also the first region in China that has entered the six world-renowned urban clusters. Figure 2 is the basic characteristic map of Yangtze River Delta.

Shanghai: Located at the midpoint of the north-south coastline of Eastern China and the estuary of the Yangtze River, Shanghai is the very core of the cities in the Yangtze River Delta, and one of the 
largest metropolitan areas with the largest population and acreage in the world. Shanghai is the center of China's economy, finance, trade, shipping, and technological innovation, has the most developed financial industry, foreign economy, and transportation network in China, and is the largest gateway for China's opening up. The regional area has a land area of 6340 square kilometers and a population of 25 million in 2018. By the end of 2018, Shanghai has the largest GDP in China and the second largest in Asia, only second to Tokyo, Japan. At the same time, the Shanghai port has the largest container throughput in the world and the first pilot free trade zone of China.

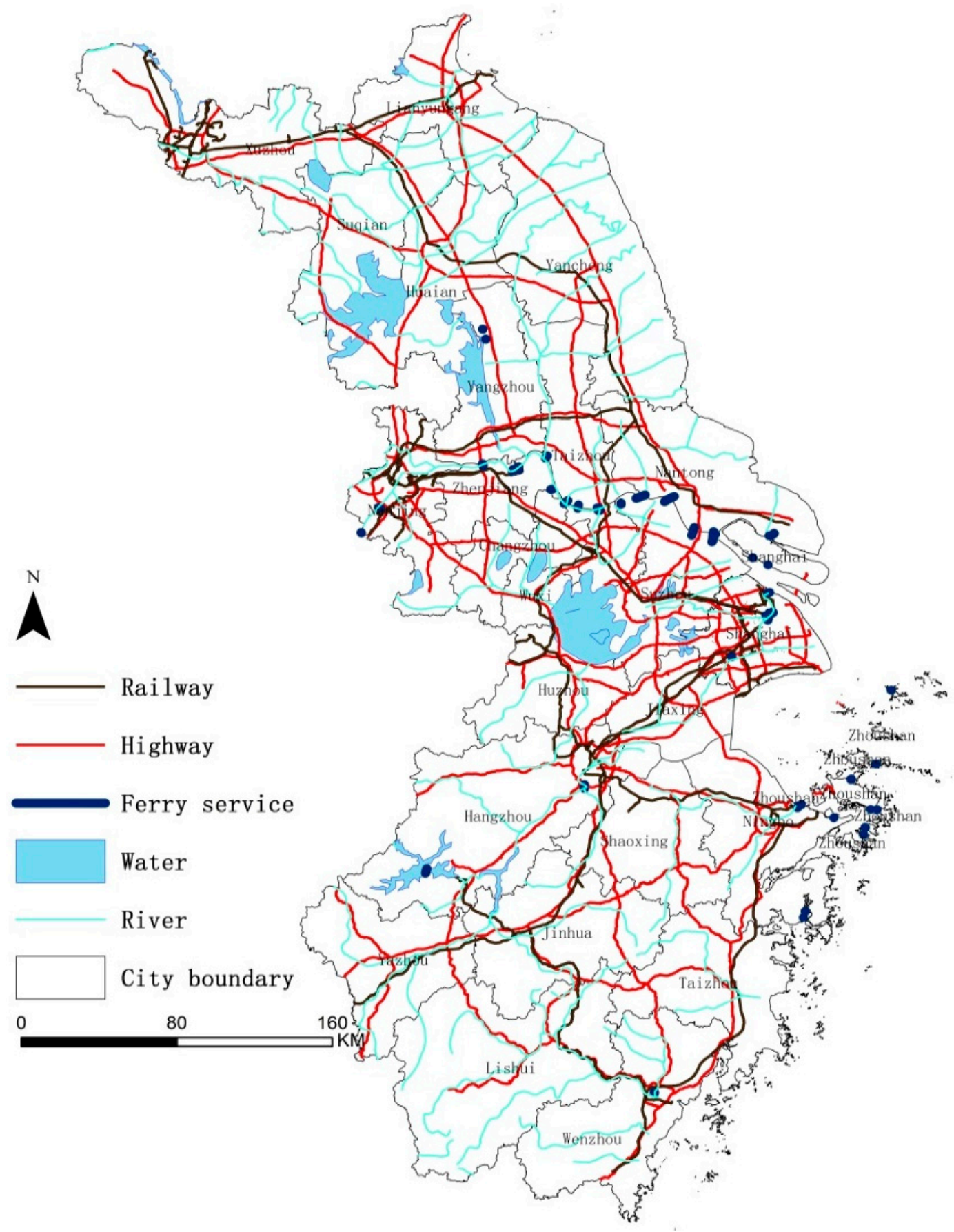

Figure 2. The basic characteristic map of Yangtze River Delta. 


\subsection{Data}

There are two types of data involved in this paper: Logistics enterprise data and statistical data of related cities.

Logistics enterprise data: In China, A-level logistics enterprises are the leader of logistics industry. A-level logistics enterprises are more perfect than other logistics enterprises in scale, function, and industry standard, and can provide relatively complete transportation, warehousing, circulation, and processing services. Therefore, for the study of China's logistics space, A-level logistics enterprises are a very suitable selection object. The data source of logistics enterprises is from China Federation of Logistics and Purchasing (CFLP). Based on the national standards of "Logistics Enterprise Classification and Evaluation Indexes" (GB/T 19680-2013) and the relevant system and method for the comprehensive evaluation of logistics enterprises of the CFLP. According to the enterprise self-inspection, application, evaluation institutions online audit and on-site evaluation, and other standardized evaluation procedures between July 2005 and December 2018, the website has published in succession a total of $4938 \mathrm{~A}$-level logistics enterprises and above in 25 batches (the stars of enterprises are divided into five grades, which decrease from 5A to A in turn.). Among these 4938 A-level logistics enterprises, we carefully selected 650 A-level logistics enterprises in Jiangsu Province, 642 A-level logistics enterprises in Zhejiang Province and 241 A-level logistics enterprises in Shanghai, totaling 1533 A-level logistics enterprises. Then, an enterprise property database was established according to the information concerning the detailed enterprise address, registration time, and cancellation time, star standard, registered capital, enterprise nature, and business scope secured through the official websites of these enterprises. Through the enterprise attributes database, the logistics enterprises are classified in detail according to the corresponding standards, in order to analyze the spatial and temporal evolution of the logistics enterprises with the corresponding standards in different time periods. The logistics enterprises mentioned below are all A-level logistics enterprises.

Related city statistics: Relevant statistical data of social and economic development are obtained from the statistical yearbooks of cities in corresponding years issued by the State Bureau of Statistics and the corresponding Provincial and Municipal Bureau of Statistics. Relevant city data mainly include changes in population, regional area, and freight turnover, which are used to show the changes of corresponding macro-indicators in the process of the spatial and temporal evolution of logistics enterprises. It should be noted that China's State Bureau of Statistics does not have a clear definition of the logistics industry at present, so we use the data of transportation, warehousing and postal service to approximately represent the logistics industry. In addition, the area of the two regions has not changed.

\section{Sprawl and Cluster of Logistics Enterprises at the Metropolitan Level: Shanghai}

The standard deviation ellipse analysis and center analysis are the most commonly used and effective methods to measure spatial distribution trend in geographic distribution tools of GIS. Firstly, we use them to measure the change of location and overall distribution trend of logistics enterprises. Then, through the kernel density analysis tool, we visualize the outward sprawl and spatial cluster of logistics enterprises, and analyze the reasons behind it combined with the background of the era and related factors.

\subsection{Location of the Logistics Enterprise in the Shanghai}

Table 1 shows the changes in the corresponding indexes of Shanghai at three different time points in 2005, 2010, and 2015, as well as the changes in the number of logistics enterprises. 
Table 1. Logistics index of Shanghai at different time nodes.

\begin{tabular}{cccccc}
\hline Logistics Index & $\mathbf{2 0 0 5}$ & $\mathbf{2 0 1 0}$ & Change (\%) & $\mathbf{2 0 1 5}$ & Change (\%) \\
\hline Population (Ten thousand) & 1778 & 2303 & +29.52 & 2415 & +4.86 \\
Freight turnover (Ten thousand tons) & 68,636 & 87,256 & +27.13 & 90,893 & +4.17 \\
Number of A-level logistics enterprises (EA) & 140 & 207 & +47.86 & 241 & +16.43 \\
Number of A-level logistics enterprises per 1000 km $\mathrm{km}^{2}(\%)$ & 22 & 33 & +50 & 38 & +15.15 \\
Direction change of Center of gravity & & & southeast & & South \\
Mean distance from Centre of gravity (KM) & 27.57 & 30.54 & +10.77 & 31.59 & +3.44 \\
\hline
\end{tabular}

Figure 3 shows the location of logistics enterprises at three different time nodes in Shanghai and the variation of the standard deviation ellipse of the geographical distribution of logistics enterprises at different time nodes. It can be seen clearly from the figure that from 2005 to 2010, the standard deviation ellipse increased significantly and moved slightly to the southeast, which indicates that the distribution trend of logistics enterprises is gradually shifting to the south. The mean distance between logistics enterprises and the center of gravity has increased by $2.97 \mathrm{~km}$. This shows that logistics enterprises have gradually begun to sprawl from the central area of the city to the suburbs. From 2010 to 2015, the variation of standard deviation ellipse was not obvious, but the mean distance between logistics enterprises and the center of gravity still increased by $1.05 \mathrm{~km}$, which is significantly lower than the $2.97 \mathrm{~km}$ from 2005 to 2010, which indicates that the phenomenon of logistics enterprises' outward sprawl persists, but the heat starts to abate.

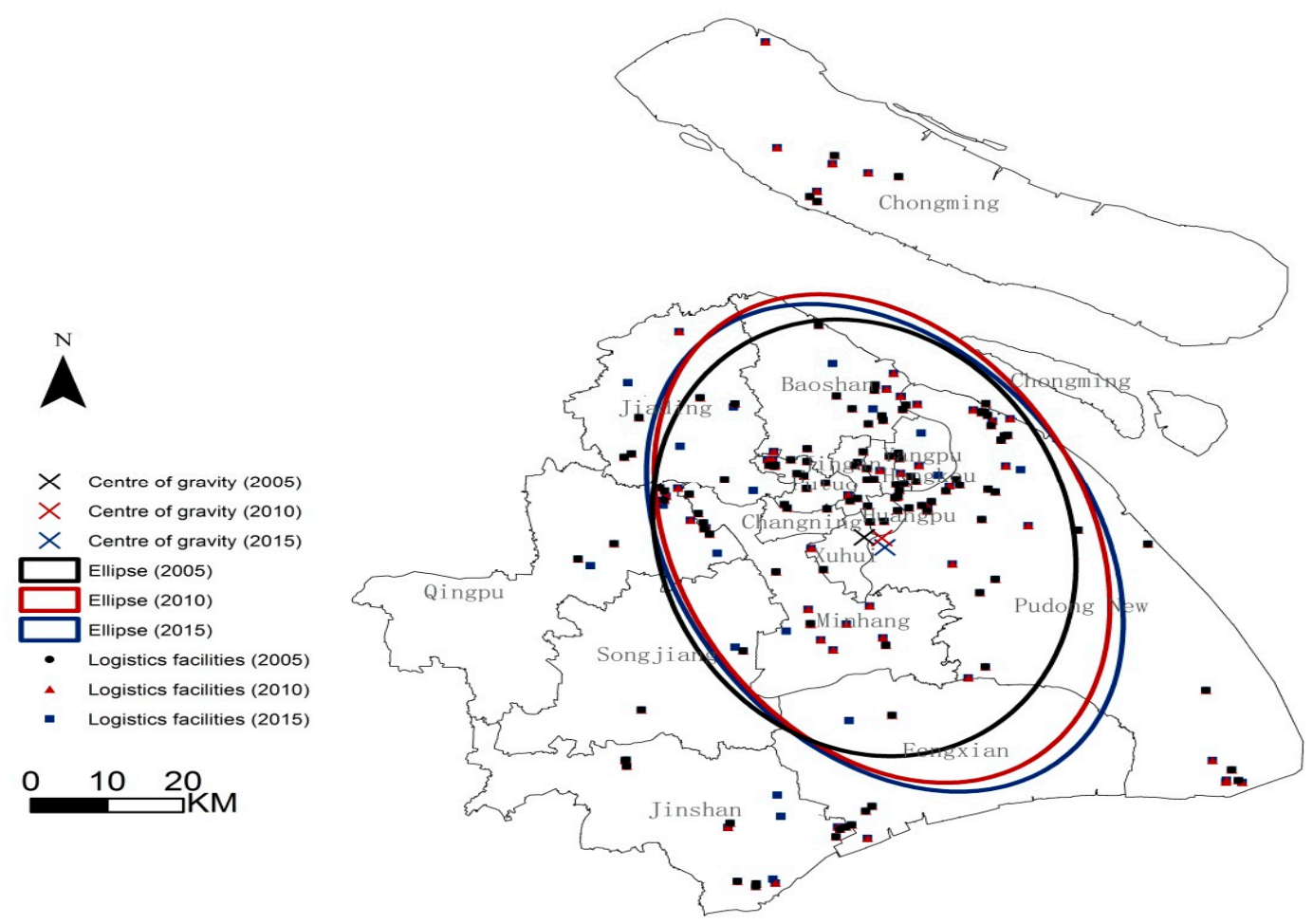

Figure 3. Location changes of logistics enterprises in Shanghai.

\subsection{Spatial and Temporal Distribution Evolution of Shanghai Logistics Enterprises}

The increase of the distance between logistics enterprises and the center of gravity confirms the occurrence of logistics sprawl phenomenon at the data level. The sprawl process of logistics enterprises can be further identified through the kernel density analysis tools in the GIS software.

Figure 4 shows the kernel density changes of Shanghai logistics enterprises at three different time nodes in 2005, 2010, and 2015. 


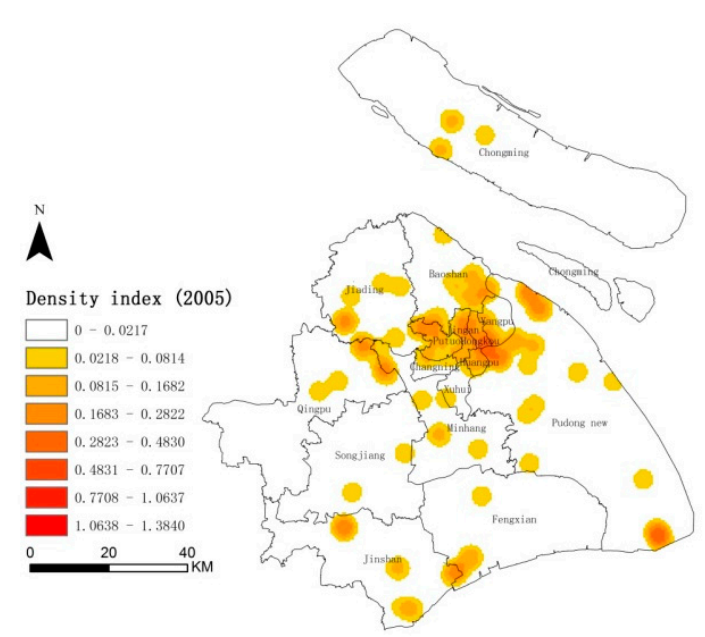

A

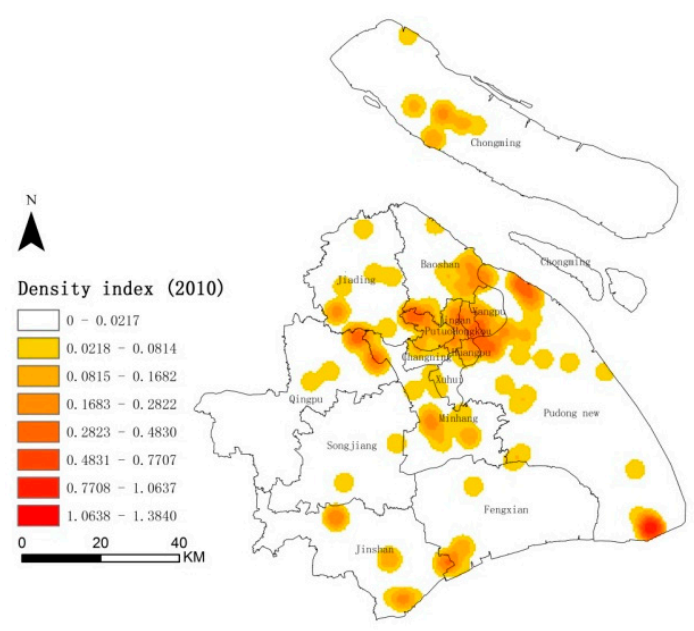

B

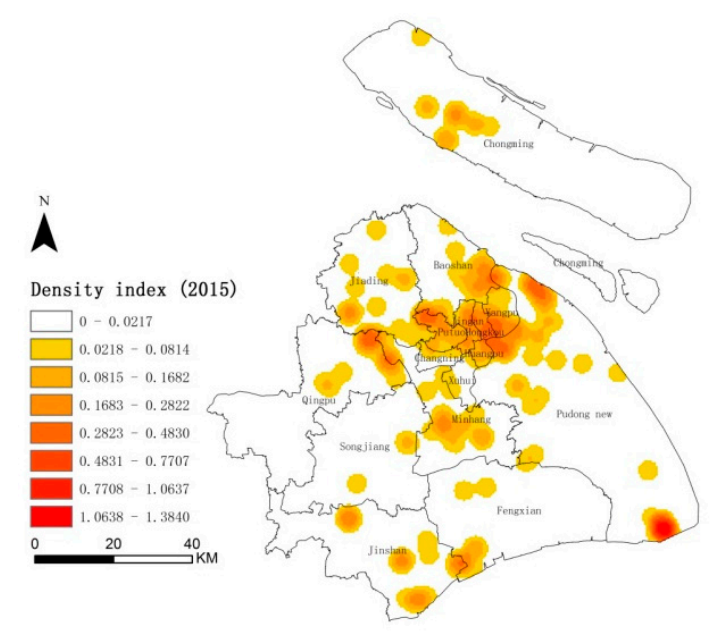

C

Figure 4. Kernel density analysis of logistics enterprises in Shanghai (A) (2005); (B) (2010); (C) (2015).

From the kernel density map, the outward sprawl process of Shanghai logistics enterprises can be clearly seen, and the spatial cluster of Shanghai logistics enterprises can also be further identified.

In general, logistics enterprises show the characteristics of transformation from "single center" to "multi-center" cluster mode [31]. Huangpu, Xuhui, Changning, Yangpu, and Hongkou districts are the core districts of Shanghai, where most of the early logistics enterprises gathered. With the passage of time, the intensity of cluster in the downtown area at the junction of Yangpu District, Hongkou District, Huangpu District, Zhabei District, and Pudong New District has gradually increased, turning it into the most important cluster place for logistics enterprises in Shanghai. Meanwhile, a number of enterprise cluster centers have been gradually formed around the cluster core, such as the junction of Qingpu District, Jiading District, and Changning District, the Southern Logistics Park of Minhang District, Pudong Waigaoqiao Bonded Logistics Park, the Steel and Metallurgical Products Logistics Base of Yanghang Town, Baoshan District, and the Northwest Comprehensive Logistics Park [32]. Logistics enterprises show a gradient decreasing distribution along the cluster core and cluster center to the periphery.

By 2015, the expansion speed of central urban cluster core and its surrounding cluster center has been further enhanced. It is worth noting that Yangshan Deep-Water Port Logistics Park and Pudong 
Airport Logistics Park in Pudong New District have gradually become important distribution areas for logistics enterprises. Due to some historical factors in modern China, Shanghai was developed as a port city. After the Reform and Opening up, relying on Shanghai's advantageous geographical location and port industry, and pursuing the strategic goal of building Shanghai into an international port, the Chinese government vigorously developed the shipping industry of the metropolis. The volume of container transportation in Shanghai has increased rapidly, which has strongly stimulated the emergence of regional logistics enterprises [33]. Meanwhile, the Logistics Industrial Park of the Chemical Industry Zone in the south of Jinshan District has gradually become an important distribution area for logistics enterprises since its establishment in 2006.

\subsection{Causes for the Spatial and Temporal Evolution of Logistics Enterprise in Shanghai}

In the era of planned economy, Shanghai was an important industrial city in China, whose industrial economy constitutes the bulk of the city's economy. Therefore, relying on its original development history, basic industries, port and waterway transportation advantages, the downtown area located in the lower reaches of the Huangpu River has concentrated a large number of productive state-owned industrial enterprises. By 1995, the number of enterprises in the downtown area accounted for $34.8 \%$ of the total number of enterprises in the city. The cluster of a large number of industrial enterprises in the central urban area within the inner ring road turned the central urban area into the growth pole of Shanghai's regional economic development. The huge market demand drives the cluster of logistics enterprises [34].

With the implementation of the Reform and Opening-up policy in China in the 1980s, planned economy began to transit gradually to market economy. In order to promote the development of private economy and attract foreign investment, and evacuate industrial enterprises in the inner ring line, the Shanghai Municipal Government has put forward the policy of adjusting industrial layout. Nine city-level industrial zones were built in Songjiang and Qingpu, and the suburban districts and counties concerned were required to offer corresponding preferential policies for enterprises. Therefore, the suburban districts for logistics enterprises further enhanced their attractiveness and became the hot spots for logistics enterprises [35].

Since China's entry into the WTO, China's economy has gradually been in line with the world. As the bellwether of China's economy, Shanghai witnesses rapid, prosperous economic development in all industries. However, due to its low average profit margin, the logistics industry is less competitive than other service industries such as finance, trade, and commerce on the market. At the same time, the land price in China's urban areas is increasing year by year. Due to the acceleration of urbanization in China, land prices in urban areas have risen rapidly. According to the principle of differential land rent, the high land rent in the city center has become an important problem for logistics enterprises to choose a site [36]. With the continuous improvement of the material living standards of urban residents, there have appeared higher requirements for the daily living environment. Noise and environmental pollution caused by some facilities in logistics enterprises are beginning to be resisted by residents [37]. Meanwhile, after the Reform and Opening up, the Chinese government has invested a lot of money in the construction of transportation network, and the infrastructure and road network planning in the suburbs are improving day by day, which also provides favorable conditions for the outward sprawl of logistics enterprises. Additionally, the industrial enterprises in the urban center tend to increase the intensity of outward migration due to environmental, cost, policy, and other factors, so the logistics demand in the urban center is correspondingly weakened. In recent decades, due to changes in technology, logistics facilities are becoming more and more efficient in centralized operations, but they also need broader land as support. The suburbs, in terms of land rent, land area, or government policies, meet the needs of modern logistics enterprises to a large extent. Under the influence of corresponding pushing and pulling force, the urban center is no longer the favorite site to be selected by logistics enterprises, and the suburbs begin to become an important selection and gathering place for logistics enterprises [38]. 


\section{Sprawl and Cluster of Logistics Enterprises at the Regional Level: Yangtze River Delta}

In the previous section, Shanghai was taken as an example to analyze the sprawl and cluster of logistics enterprises at the metropolitan level. As the kernel city in the Yangtze River Delta region, Shanghai witnessed the phenomenon of the sprawl and cluster of logistics enterprises. In this section, we will analyze the spatial and temporal evolution of the logistics enterprises at the regional level in the Yangtze River Delta region.

\subsection{Location of the Logistics Enterprise in the Yangtze River Delta}

Table 2 shows the changes in the corresponding indexes of Yangtze River Delta at three different time points in 2005, 2010, and 2015, as well as the changes in the number of logistics enterprises.

Table 2. Logistics index of Yangtze River Delta at different time nodes.

\begin{tabular}{cccccc}
\hline Logistics Index & $\mathbf{2 0 0 5}$ & $\mathbf{2 0 1 0}$ & Change (\%) & 2015 & Change (\%) \\
\hline Population (Ten thousand) & 14,151 & 15,619 & +10.37 & 15,930 & +1.99 \\
Freight turnover (Ten thousand tons) & 306,372 & 437,308 & +42.74 & 491,122 & +12.31 \\
Number of A-level logistics enterprises (EA) & 795 & 1287 & +61.89 & 1533 & +19.11 \\
Number of A-level logistics enterprises per 100,000 km (\%) & 38 & 61 & +60.53 & 73 & 19.67 \\
Direction change of Center of gravity & & & Southwest & & Southwest \\
Mean distance from Centre of gravity (KM) & 153.99 & 162.32 & +5.41 & 165.63 & +2.04 \\
\hline
\end{tabular}

Figure 5 shows the location of logistics enterprises in the Yangtze River Delta region at three different time nodes and the variation of the standard deviation ellipse of the geographical distribution of logistics enterprises at different time nodes.

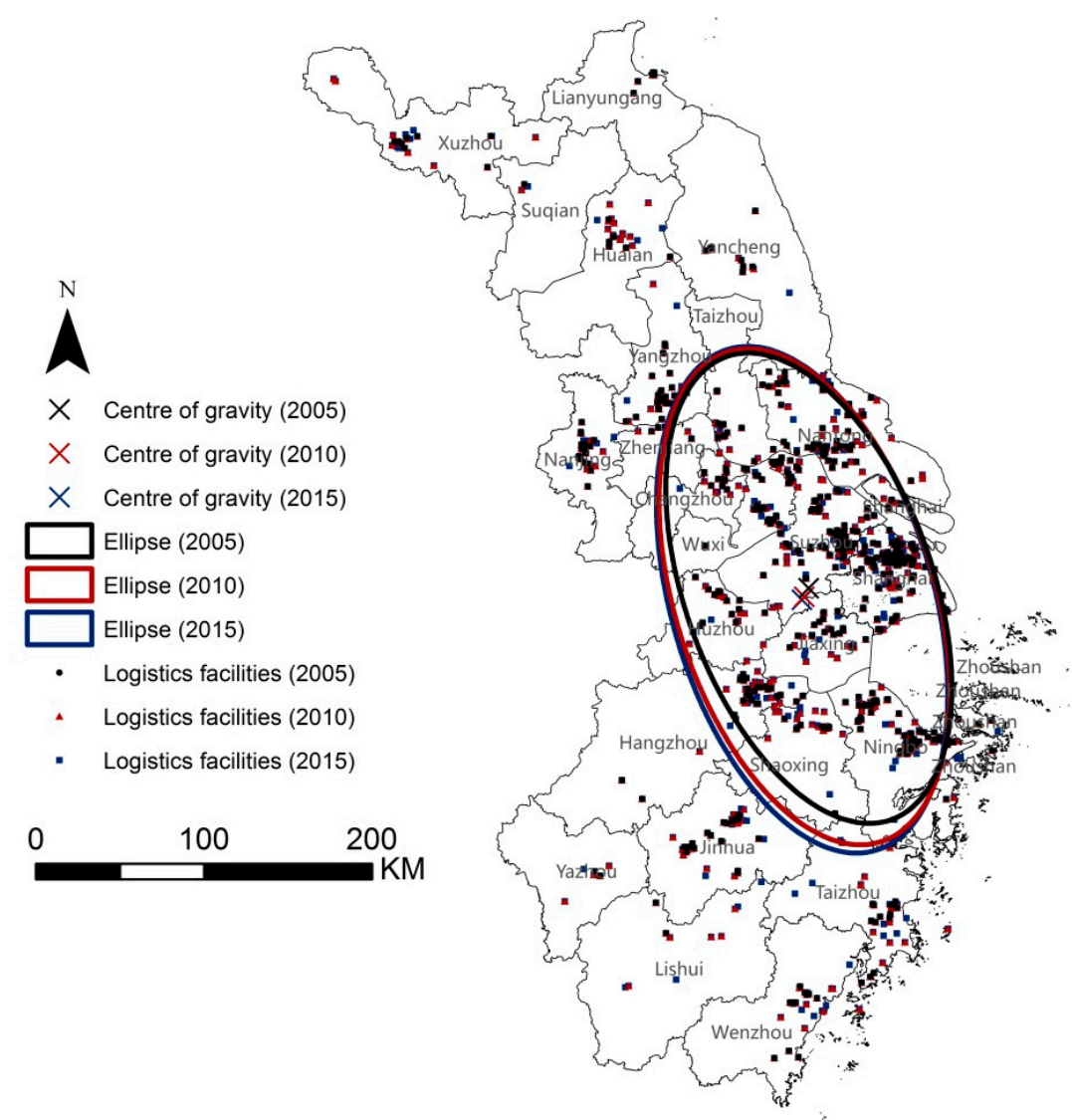

Figure 5. Location changes of logistics enterprises in Yangtze River Delta. 
As can be seen from the picture, the standard deviation ellipse of logistics enterprises gradually shifted to the south from 2005 to 2010 and then to 2015, and the trend from 2005 to 2010 was significantly higher than that from 2010 to 2015. This shows that the distribution trend of logistics enterprises is gradually shifting to the south, which is consistent with the distribution trend of logistics enterprises in Shanghai. In terms of the mean distance between logistics enterprises and the center of gravity, from 2005 to 2010, the mean distance increased by $8.33 \mathrm{~km}$, and from 2010 to 2015, the mean distance increased by $3.31 \mathrm{~km}$, both of which are higher than those of Shanghai, which indicates that the outward sprawl of logistics enterprises in the Yangtze River Delta region has occurred, and is more significant than that in Shanghai. It is worth noting that in Shanghai or the Yangtze River Delta region, in the comparison of the data between the first five years and the second five years, the data from 2005 to 2010 are significantly higher than the data from 2010 to 2015 either in the degree of change of the distribution trend of the standard deviation ellipse, the growth of the number of logistics enterprises, or the growth of the mean distance. The reason for the disparity is worth exploring, so we will further discuss it in the following sections.

\subsection{Spatial and Temporal Distribution Evolution of Yangtze River Delta Logistics Enterprises}

Figure 6 shows the distribution of kernel density at three different time nodes of logistics enterprises in the Yangtze River Delta.

It can be clearly seen from the picture that the outward sprawl process of logistics enterprises increases with time. In general, the spatial pattern of logistics in the Yangtze River Delta region is characterized by the evolution from "two-center, multi-level and multi-point" to "multi-center, two-cluster and multi-point" [39].

"Two-center, multi-level and multi-point" is the spatial distribution pattern of regional logistics in the Yangtze River Delta at the beginning of the 21st century, namely, "with Shanghai and Suzhou as the core, some cities as multiple logistics growth poles (Nanjing, Nantong, Ningbo, Jinhua and others ), and other cities as multiple logistics nodes (other cities in the Yangtze River Delta)".

"Multi-center, two-cluster, and multi-point" refers to the new regional logistics spatial pattern formed under the promotion of the construction of international shipping center in Shanghai, the construction of regional logistics center in Nanjing, and the integrated construction of Ningbo and Zhoushan ports. That means to gradually form multiple logistics centers (Shanghai, Suzhou, Jinhua, and Ningbo), two logistics groups (logistic group in northern Yangtze River Delta comprising Nanjing, Changzhou, Zhenjiang, Taizhou, Nantong, and Yangzhou, and logistics group around the Hangzhou Bay comprising Hangzhou, Huzhou, Jiaxing, Ningbo, and Shaoxing), and multiple points (other cities in the Yangtze River Delta) [40].

The kernel density distribution maps of logistics enterprises in Shanghai and the Yangtze River Delta show that primarily the phenomenon of logistics cluster began to gradually occur in the process of logistics sprawl. It is worth noting that in the process of logistics sprawl, most of the areas where logistics enterprises tend to cluster are transportation hubs, such as Shanghai, Jinhua, Ningbo, and Shaoxing. Combined with the kernel density distribution map and the traffic network of the Yangtze River Delta region, this shows that transportation infrastructure and accessibility are one of the important factors in the process of location selection of logistics enterprises. 


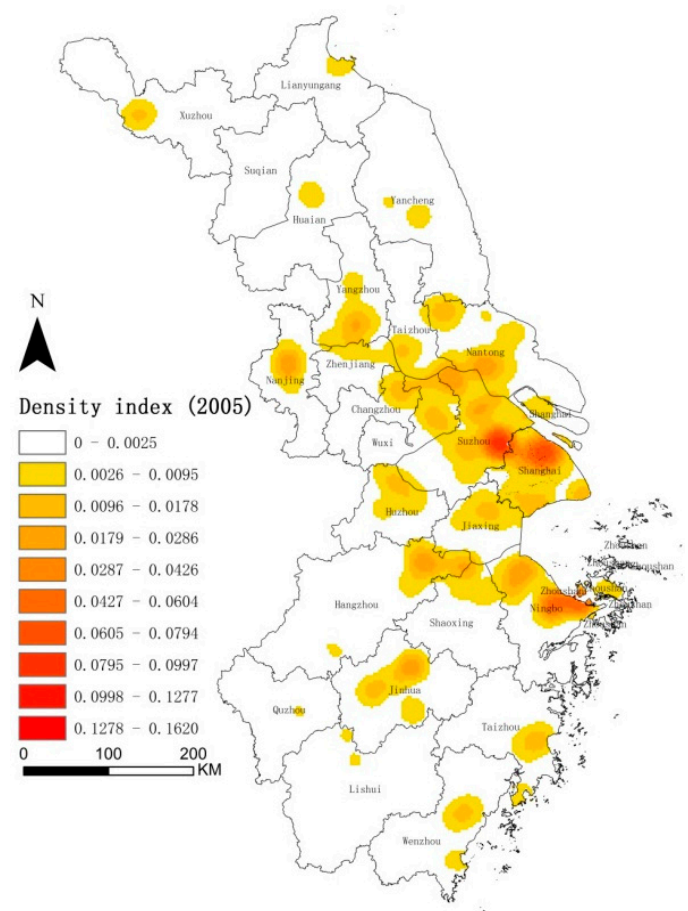

A

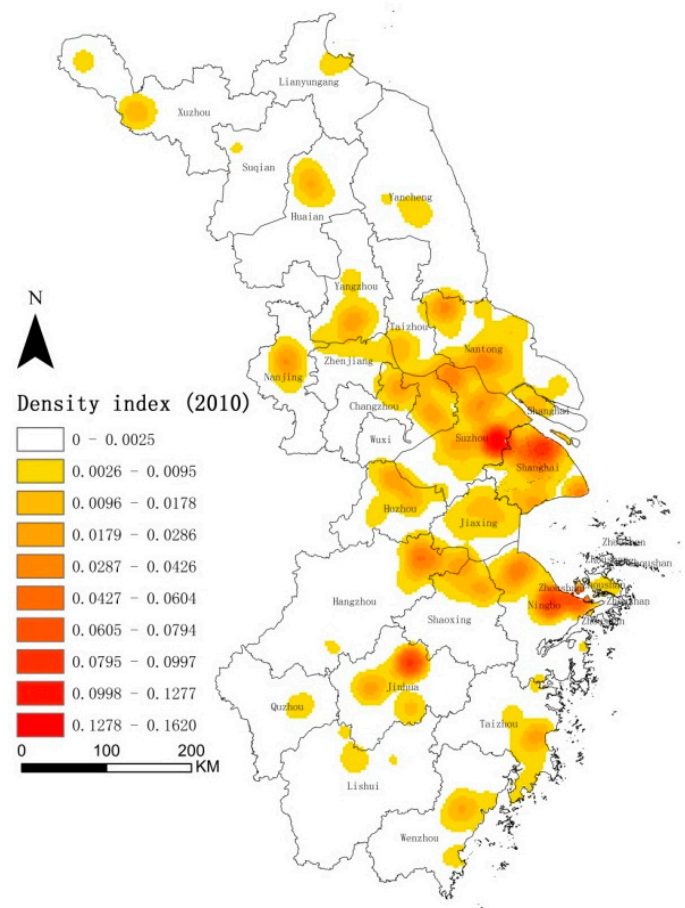

B

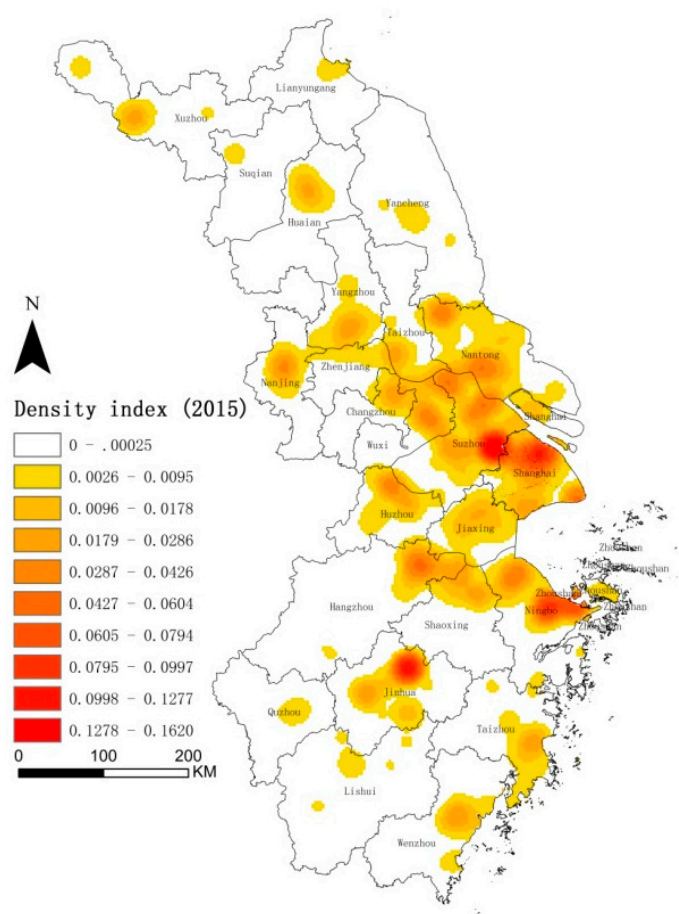

C

Figure 6. Kernel density analysis of logistics enterprises in Yangtze River Delta (A) (2005); (B) (2010); (C) (2015).

\subsection{Causes for the Spatial and Temporal Evolution of Logistics Enterprise in Yangtze River Delta}

Due to the deepening of China's economic reform, all the metropolitan areas in the Yangtze River Delta region have experienced rapid development, and logistics enterprises in various metropolitan 
areas have also grown rapidly. Through the application of hot spot analysis tools in the GIS software, we can further identify the cold and hot spot of the cluster of logistics enterprises among different metropolitan areas in the region, and analyze the reasons for its spatial and temporal evolution.

Figure 7 shows the distribution hotspots of logistics enterprises in the Yangtze River Delta region at three time periods.

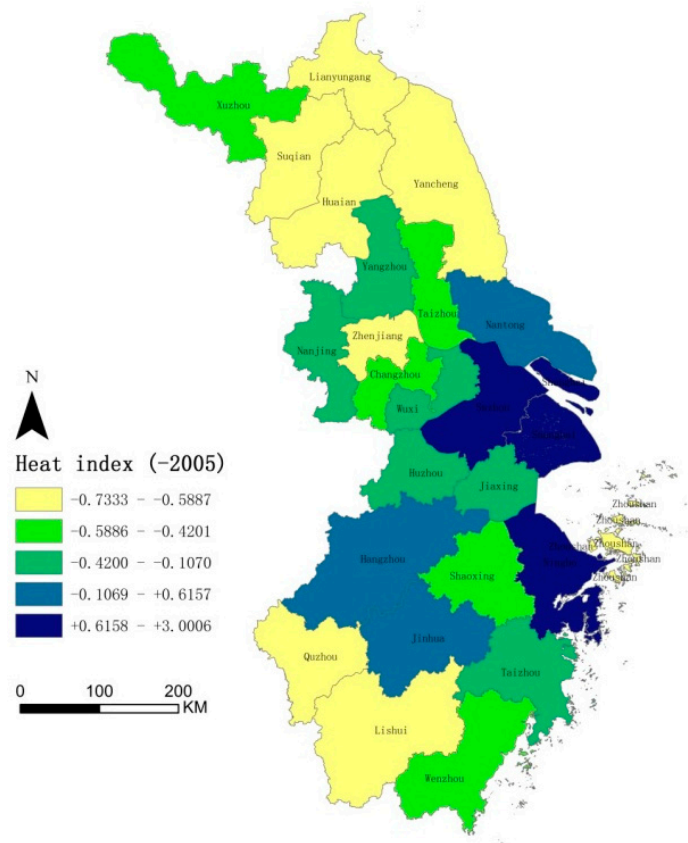

A

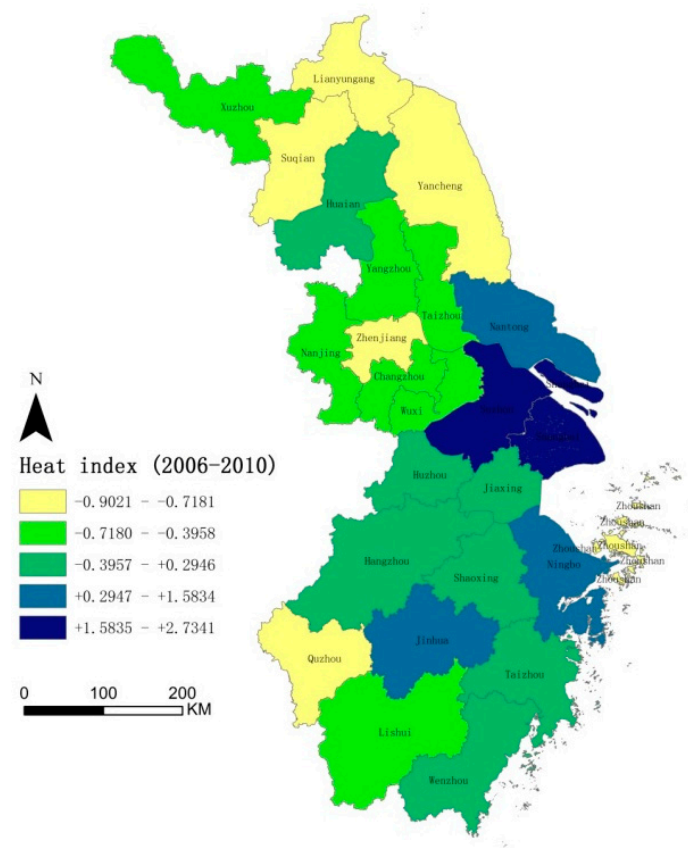

B

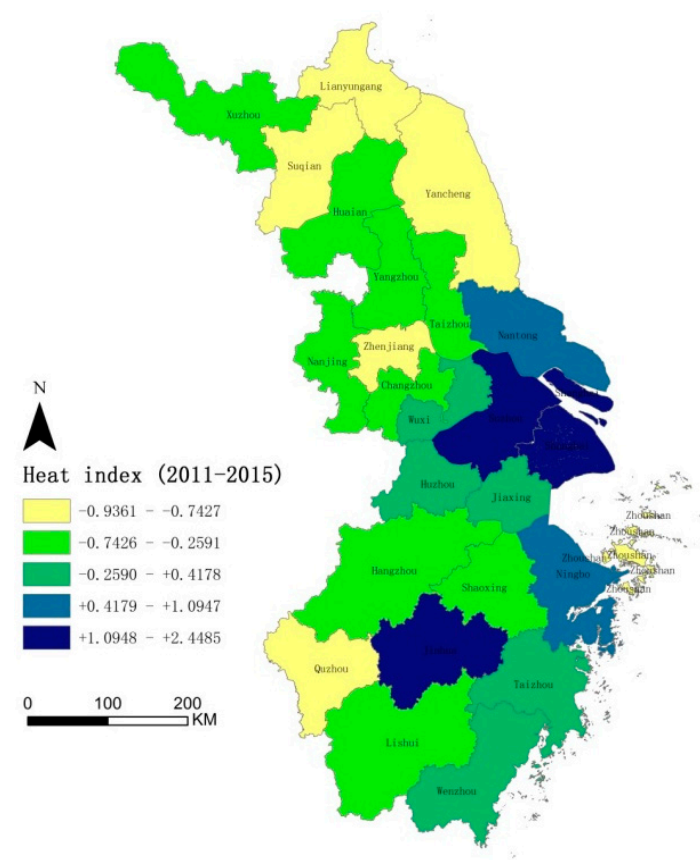

C

Figure 7. Hotspot analysis of logistics enterprises in Yangtze River Delta. (A) (-2005); (B) (2006-2010); (C) (2011-2015). 
Before 2005, the development of China's logistics industry was still in in the phase of initiation, most of the logistics enterprises were state-owned enterprises that relied on the original development history. Due to the particularity of planned economy in the early stage of China's development, these logistics enterprises were mostly distributed in some cities with a history of development, such as Shanghai, Suzhou, and Ningbo, followed by Hangzhou, Jinhua, Nanjing, and Nantong at a lower level. These cities have attracted many private enterprises by relying on the continuing development foundation and the advantages of port and transportation. They have become the hot spots where logistics enterprises tend to distribute at the initial stage [41]. Some cities in the north and south of the Yangtze River Delta have become cold spots for logistics companies to avoid or escape from in choosing a location due to their geographical and traffic disadvantages.

From 2006 to 2010, with the deepening of China's Reform and Opening up policy, the rapid growth of private enterprises and the influx of foreign-funded enterprises, the spatial and temporal distribution of logistics enterprises in the Yangtze River Delta gradually changed. The acceleration of urbanization is accompanied by the soaring price of land. As a provincial capital city, Hangzhou and Nanjing were developing rapidly. High land rents and corresponding policy factors made logistics companies no longer regard these cities as hot spots for site selection. Due to their high openness and industrial synergy effects, Shanghai and Suzhou remain hot spots despite their high land prices, attracting many foreign-funded enterprises. Nantong, Ningbo, and Jinhua have become hot spots for logistics enterprises because of their low land prices, port advantages, and continuous improvement of transportation network [42].

From 2010 to 2015, with the rapid development of China's logistics industry, due to the adjustment of industrial structure and the promotion of industrial transformation and upgrading, the spatial distribution of regional logistics industry exhibited an obvious agglomeration trend. The central government began to gradually devolve power to local governments, so that local governments gained greater dominance [43]. Each region combined its own location conditions and industrial advantages and disadvantages, to form different industrial circles [44]. For example, Shanghai focused on the development of financial, shipping, and other service industries and strove to build itself into an "international shipping center". Suzhou focused on the development of modern logistics, technology, cultural tourism, and other service industries. Ningbo and Nantong focused on the development of petrochemical, shipbuilding, and other port-type industries. Jinhua focused on the development of services such as automobiles and medicine [45]. These cities have become hot spots chosen by logistics enterprises according to their own characteristics and different tendencies. The spatial distribution pattern of regional logistics has been taking shape.

\section{Discussion and Suggestion}

The sprawl and cluster of logistics enterprises in Shanghai and Yangtze River Delta gives us a preliminary understanding of the spatial and temporal distribution characteristics of two different levels of logistics enterprises from 2005 to 2015. Additionally, we briefly analyze the reasons for the spatial and temporal distribution of logistics enterprises in 10 years. Our discussion on several significant phenomena is as follows:

1. The growth of the number of logistics enterprises: The proportion of logistics enterprises in Shanghai and the Yangtze River Delta in 10 years increased by $72.14 \%$ and $92.83 \%$, respectively. As a producer service industry, the large-scale growth of the corresponding logistics enterprises indicates that the logistics industry has been paid more and more attention to in the process of economic development, and has gradually become an indispensable part of the whole supply chain of different industries. Interestingly, the growth rate of logistics enterprises of the second five years was significantly less than that of the first five years. After decades of development, due to the adjustment of industrial structure and the transformation and upgrading of enterprises, some small-scale logistics enterprises began to be annexed by larger-scale logistics enterprises with broader business capabilities [46]. Furthermore, due to the development of third-party logistics, more and more enterprises tend to 
outsource logistics business to more specialized third-party logistics enterprises in logistics business so as to concentrate on their main business, so they no longer establish corresponding logistics enterprises for their own products and services [47]. All these have reduced the growth of logistics enterprises to a certain extent, and made the logistics industry develop towards a more specialized direction. At the same time, due to the emergence of industrial cluster effect, when choosing the suburb as the site selection object, logistics enterprises would also consider factors such as the cluster location of the corresponding industry and the distance from other key traffic nodes, which has slowed down the speed of outward sprawl of logistics enterprises.

2. Factors influencing the sprawl of logistics enterprises: (1) Government policy: Most of the logistics enterprises are service enterprises, who bring less profit margins to cities than finance, trade, commerce, and other industries. With the acceleration of urbanization, the supply of urban land is becoming further tense. Therefore, in the process of urban land space reorganization, logistics enterprises will find it difficult to enjoy the corresponding preferential land policies provided by the government. Moreover, due to institutional reasons, China's market economy is still guided by the government's macro-control. Furthermore, in order to alleviate the urban congestion and improve the urban environment, the government mostly relocates logistics enterprises out of the urban center in its implementation of macro-control strategies [48]. (2) Land price: Land prices in China's metropolitan areas have multiplied several times in the past few decades. Lower profit margins of logistics enterprises can hardly support the cost of construction in urban centers, which has also begun to stimulate logistics enterprises to stay away from urban centers. (3) Technological progress: The progress of science and technology further perfects the function of modern logistics facilities, but the demand for land area is more enlarged. With the continuous improvement of transportation network in suburban areas, suburban areas have greater advantages than urban centers in terms of land price or land area, which provides a huge attraction for the outward sprawl of logistics enterprises [49].

3. Factors influencing the cluster of logistics enterprises: (1) Regional policy orientation: In the past few decades of China's rapid economic development, the decentralization of central government power has given more leadership to regional governments. The governments of metropolitan areas began to provide preferential policies for the corresponding logistics industry on the basis of their own superior industries, attracting and merging other logistics enterprises, and gradually forming a number of cluster industrial belts [50]. (2) Transportation infrastructure and accessibility: Combining the kernel density distribution map of logistics enterprises with the traffic network of the Yangtze River Delta, we can find that the transportation hub is the hot area where logistics enterprises tend to cluster. Transportation cost is the highest proportion of the cost of logistics enterprises. Accessibility and the perfection of transportation infrastructure can reduce a lot of transportation costs for logistics enterprises, while greatly improving transport efficiency. (3) Industrial cluster effect: With the development concept of logistics industry in the Yangtze River Delta becoming more and more mature, logistics enterprises are beginning to realize that sharing infrastructure and division of labor and cooperation can be achieved through industrial cluster, thus greatly improving the operational efficiency of logistics enterprises. Furthermore, the cumulative effects of professional knowledge, production skills, and market information generated within industrial cluster provide an important source of innovation for enterprises [51].

Similar to capitalist countries, land prices, government guidance, gradual improvement of suburban infrastructure, and industrial cluster effect are the main factors affecting the change of logistics space. For developed capitalist countries, land price may be the first factor to be considered. It is worth noting that, due to the difference of economic systems, the government's macro-control policies have a greater impact on the sprawl and cluster of logistics enterprises than land prices in China.

4. Impact of the logistics sprawl on the sustainable development of society: In the 10 years of the outward sprawl of logistics enterprises, the urban spatial structure of Shanghai and the Yangtze River Delta has also changed. Large storage centers and distribution nodes have begun to 
move to the periphery of the city, leaving only core business organizations in the city center, though this has brought about the negative impacts of an increase to some extent in mileage and in carbon emissions [52]. However, at the same time, the congestion and environment in the city center have been greatly improved and the loss of time has been reduced. This is especially important in the information society, for time is a very important source of profit for some industries and residents. With the reorganization of urban spatial structure, some employees have moved out with the sprawl of logistics enterprises, which can also alleviate the employment pressure in the urban center to a certain extent. It also has a very positive impact on the rational allocation of urban resources, the increase of the continuity of public transportation, and the improvement of urban planning [53]. In general, the positive impact brought by the outward sprawl of logistics facilities is obviously greater than the negative impact, which plays a strong guiding role in the process of social sustainable development.

5. Impact of the logistics cluster on the sustainable development of society: The industrial cluster effect is the inevitable requirement of urban development in the 21st century and a crucial link in the process of social sustainable development. The concentration of logistics enterprises in geographic space will aggravate the industrial cluster effect, which will have an impact on the economy, society, and environment [54]. In terms of economic benefits, it is conducive to reducing transportation costs, promoting regional economic integration, and improving social productivity. In terms of social impact, it is conducive to creating employment opportunities, improving urban staffing, and enhancing regional influence. In terms of environmental impact, it is conducive to improving urban structure, alleviating urban congestion, and reducing carbon emissions [55].

In view of the current situation of logistics space in the Yangtze River Delta, we put forward some suggestions on some phenomena:

(1) Strengthen the government's macro-control: Due to the advantages of China's unique market economy system, the government should increase the support of logistics policy, and grasp the development trend of logistics from the macro perspective. Then, promote the flow of logistics resources in the region, and guide the integration of logistics space and urban space rationally.

(2) Reasonably guide the evolution of logistics space to sustainable development: Each region should rationally locate the urban logistics niche, fully considering the coordination between logistics space and society, economy, environment, and employment. Then, provide reasonable guiding principles for new and old logistics enterprises, and promote the sustainable development of urbanization process.

(3) Strengthen regional linkage development and promote logistics development networking: Each region should make full use of its own advantages, strengthening the construction of logistics networking, promoting logistics informatization, and standardization. The government should coordinate the strengths and weaknesses of each region and make use of the industrial cluster effect to improve the overall efficiency of logistics.

\section{Conclusions}

Logistics sprawl and cluster have aroused the interest of scientific planning researchers in many cities in the world, and quite a few scholars have analyzed and studied some regions in developed countries such as the United States, Japan, France, and Sweden. However, most previous case studies were focused on the urban areas of developed capitalist countries, and there were great deficiencies in the case studies of developing socialist countries. As the largest developing socialist country in the world, China has achieved rapid economic development with its unique economic system since the 21st century. The case study of the Yangtze River Delta region, the most economically developed region in China and an important gateway to the world, can greatly enrich the current literature on the spatial and temporal distribution of logistics space. In this paper, through collecting the data of A-level logistics enterprises in the Yangtze River Delta from 2005 to 2015, we studied the phenomenon of the outward sprawl of logistics enterprises and the cluster formed in the geographical space distribution. The analysis was carried out from two perspectives: The metropolitan and the 
regional level. Then, based on the regional development of the Yangtze River Delta in the past decades, we analyzed the causes of its emergence from the perspective of policy and economy, and its impact on the process of urbanization from the perspective of sustainability. Finally, we provide relevant suggestions for the government and logistics enterprises. The conclusions are as follows:

1. The phenomenon of logistics sprawl and logistics cluster has occurred in different degrees of sprawl in the Yangtze River Delta region and Shanghai. Compared with the sprawl of some developed countries such as the United States and Japan, the logistics sprawl of Shanghai and the Yangtze River Delta region is at a medium-high level. This shows that with the development of economy, the phenomenon of logistics sprawl not only appears in developed capitalist countries, but also becomes a common phenomenon faced by developing socialist countries.

2. The centrifugal forces that promote the sprawl of logistics enterprises include: (1) Government policy; (2) land price; (3) technological progress.

3. The centripetal force to promotes the cluster of logistics enterprises are: (1) Regional policy orientation; (2) transportation infrastructure and accessibility; (3) industrial cluster effect.

Author Contributions: M.H. and L.Z. conceived the conception and collected documents. J.L. and X.W. screened eligible papers carefully and offered reasonable suggestions; L.Z. wrote the manuscript. All authors have read and approved the final manuscript.

Funding: This work is supported by the Natural Science Foundation of Jiangsu Province [Grants No BK20160512]; the Humanities and Social Science Youth Foundation of the Ministry of Education of China [Grants No 16YJCZH027]; the National Natural Science Foundation of China [Grant No 71772080].

Conflicts of Interest: The authors declare no conflict of interest.

\section{References}

1. Wei, J.G. Strategic Development of China's Logistics Industry; China Ocean Shipping: Shanghai, China, 2018; Volume 10, pp. 66-68.

2. Yang, H.L.; Lin, W. Evolution of competition in energy alternative pathway and the influence of energy policy on economic growth. Energy 2015, 88, 223-233. [CrossRef]

3. Zhou, W.Q.; Chen, L. Research on the inventory control of the remanufacturing reverse logistics based on the quantitative examination. Sci Iran 2017, 24, 741-750. [CrossRef]

4. He, M.L.; Shen, J.R. Logistics Space: A Literature Review from the Sustainability Perspective. Sustainability 2018, 10, 2815. [CrossRef]

5. Hepu, A.W.; Yang, D.G. Progress and prospects of logistics geography research. Prog. Geogr. 2012, 31, 231-238.

6. Long, X.; Chao, W. Environmental efficiency for 192 thermal power plants in the Yangtze River Delta considering heterogeneity: A metafrontier directional slacks-based measure approach. Renew. Sust. Energ. Rev. 2018, 82, 3962-3971. [CrossRef]

7. Sakai, T.; Kawamura, K. Spatial reorganization of urban logistics system and its impacts: Case of Tokyo. J. Transp. Geogr. 2017, 60, 110-118. [CrossRef]

8. Heitz, A.; Dablanc, L. Spatial patterns of logistics facilities in Gothenburg, Sweden. J. Transp. Geogr. 2018. [CrossRef]

9. Dablanc, L.; Ogilvie, S. Logistics Sprawl: Differential Warehousing Development Patterns in Los Angeles, California, and Seattle, Washington. Transp. Res. Rec. J. Transp. Res. Board 2014, 2410, 105-112. [CrossRef]

10. Heitz, A.; Dablanc, L. Logistics Spatial Patterns in Paris: Rise of Paris Basin as Logistics Megaregion. Transp. Res. Rec. J. Transp. Res. Board 2015, 2477, 76-84. [CrossRef]

11. Woudsma, C.; Jakubicek, P. Logistics Sprawl in North America: Methodological Issues and a Case Study in Toronto. Transp. Res. Procedia 2016, 12, 474-488. [CrossRef]

12. Han, F.; Xie, R. The effects of urban agglomeration economies on carbon emissions: Evidence from Chinese cities. J. Clean. Prod. 2018, 172, 1096-1110. [CrossRef]

13. Shen, Y.F.; Wang, N.Z. Research on spatial distribution and evolution characteristics of Logistics in the Yangtze River Delta region. Econ. Geogr. 2011, 31, 618-623. 
14. Lan, S.; Yang, C. Data analysis for metropolitan economic and logistics development. Adv. Eng. Inform. 2017, 32, 66-76. [CrossRef]

15. Dablanc, L.; Rakotonarivo, D. The impacts of logistics sprawl: How does the location of parcel transport terminals affect the energy efficiency of goods'movements in Paris and what can we do about it? Procedia Soc. Behav. Sci. 2010, 2, 6087-6096. [CrossRef]

16. Bowen, J.T. Moving places: The geography of warehousing in the US. J. Transp. Geogr. 2008, 16, 379-387. [CrossRef]

17. Dablanc, L.; Ross, C. Atlanta: A mega logistics center in the Piedmont Atlantic Megaregion (PAM). J. Transp. Geogr. 2012, 24, 432-442. [CrossRef]

18. Cidell, J. Concentration and decentralization: The new geography of freight distribution in US metropolitan areas. J. Transp. Geogr. 2010, 18, 363-371. [CrossRef]

19. Van Den Heuvel, F.P.; De Langen, P.W. Spatial concentration and location dynamics in logistics: The case of a Dutch province. J. Transp. Geogr. 2013, 28, 39-48. [CrossRef]

20. Li, G.Q.; Jin, F.J. Location Characteristics and Differentiation Mechanism of Beijing Logistics Industry Based on POI. J. Geogr. 2017, 72, 1091-1103.

21. Jiang, T.Y.; Wu, C.T. Research on temporal and spatial pattern characteristics of grade A logistics enterprises in Zhejiang province. Geogr. Sci. 2017, 37, 1720-1727.

22. Aljohani, K.; Thompson, R.G. Impacts of logistics sprawl on the urban environment and logistics: Taxonomy and review of literature. J. Transp. Geogr. 2016, 57, 255-263. [CrossRef]

23. Rivera, L.; Sheffi, Y. Logistics agglomeration in the US. Transp. Res. Part A Policy Pract. 2014, 59, $222-238$. [CrossRef]

24. Cui, Y.Y.; Song, B.L. Logistics agglomeration and its impacts in China. Transp. Res. Procedia 2017, 25, 3875-3885. [CrossRef]

25. Heitz, A.; Beziat, A. The Parcel Industry in the Spatial Organization of Logistics Activities in the Paris Region: Inherited Spatial Patterns and Innovations in Urban Logistics Systems. Transp. Res. Procedia 2016, 12, 812-824. [CrossRef]

26. Cao, W.D. The spatial pattern and evolution of the location of urban logistics enterprises: A case study of Suzhou. Geogr. Res. 2011, 30, 1997-2007.

27. Alho, A.R.; De E Silva, J.A. Utilizing urban form characteristics in urban logistics analysis: A case study in Lisbon, Portugal. J. Transp. Geogr. 2015, 42, 57-71. [CrossRef]

28. Sakai, T.; Kawamura, K. Logistics Facility Distribution in Tokyo Metropolitan Area: Experiences and Policy Lessons. Transp. Res. Procedia 2016, 12, 263-277. [CrossRef]

29. Kumar, I.; Zhalnin, A. Transportation and logistics cluster competitive advantages in the U.S.regions: A cross-sectional and spatio-temporal analysis. Res. Transp. Econ. 2017, 58, 294-392. [CrossRef]

30. Xu, X.X.; Wang, Y.H. Study on spatial spillover effects of logistics industry development for economic growth in the Yangtze River Delta city Cluster based on spatial durbin model. Int. J. Environ. Res. Public Health 2017, 14, 1508. [CrossRef]

31. Cui, Y.Y.; Song, B.L. Analysis of logistics spatial evolution and influencing factors in the Yangtze River Delta region. J. Cent. China Norm. Univ. 2015, 302-306.

32. Zhu, S.Q. Research on the Evolution and Mechanism of Urban Logistics Space in Shanghai. Master's Thesis, Anhui Normal University, Wuhu, China, 2014.

33. Liang, S.B.; Cao, Y.H. Spatial pattern evolution of port logistics enterprises in Shanghai metropolitan area. Geogr. Res. 2013, 32, 1448-1456.

34. Cao, Y.H.; Song, Y.Q. Research on spatial pattern of urban industry in Shanghai based on point data. Geogr. Res. 2015, 34, 1708-1720.

35. Zhao, X.Z.; Ning, Y.M. The evolution of foreign capital production space in shanghai and its influencing factors. J. Geogr. Sci. 2011, 66, 1390-1402.

36. Li, G.Q.; Jin, F.J. Spatial pattern of China's logistics industry based on logistics heat. Prog. Geogr. 2015, 34, 629-637.

37. Strale, M. Logistics sprawl in the Brussels metropolitan area: Toward a socio-geographic typology. J. Transp. Geogr. 2019. [CrossRef]

38. Liu, S.Z.; Li, G.Q. Location choice behavior and grade differences of chinese star warehouses. Prog. Geogr. 2017, 36, 843-852. 
39. Zhang, D.; Cao, W.D. The temporal and spatial pattern evolution characteristics and mechanism of logistics development efficiency in the Yangtze River Delta. Econ. Geogr. 2014, 34, 103-110.

40. Xie, S.H.; Cai, H.Y. Spatial agglomeration and cause analysis of China's logistics industry. Ind. Technol. Econ. 2015, 4, 51-58.

41. Cai, H.Y.; Xie, S.H. Research on the clustering of logistics industry in the Yangtze River Delta and its influencing factors. J. Zhejiang Shuren Univ. 2015, 15, 28-33.

42. Xie, S.H.; Cai, H.Y. The spatial and temporal evolution of the logistics industry development in the Yangtze River Delta and its influencing factors. World Geogr. Res. 2015, 31, 118-125.

43. Yuan, Q.; Zhu, J.R. Logistics sprawl in Chinese metropolises: Evidence from Wuhan. J. Transp. Geogr. 2019, 74, 242-252. [CrossRef]

44. Wang, N.Z.; Shen, Y.F. Research on spatial integration of regional logistics-An empirical study based on integration of the Yangtze River Delta. Reg. Res. Dev. 2011, 30, 36-41.

45. Cai, H.Y.; Xu, Y.Z. Research on the development pattern and influence mechanism of logistics industry in the Yangtze River Delta-Based on the perspective of spatial economics. East China Econ. Manag. 2016, 30, 15-23.

46. Sakai, T.; Kawamura, K. Locational dynamics of logistics facilities: Evidence from Tokyo. J. Transp. Geogr. 2015, 46, 10-19. [CrossRef]

47. Liu, S.J.; Ma, J. Diversification of Logistics Business and Enterprise Performance: Based on the Data Analysis of China's Logistics Listed Companies from 2003 to 2012. Ind. Eng. Manag. 2015, 20, 144-151.

48. Li, T.; Ge, B. Impacts of state-led and bottom-up urbanization on land use change in the peri-urban areas of Shanghai: Planned growth or uncontrolled sprawl? Cities 2017, 60, 476-486. [CrossRef]

49. Woudsma, C.; Jakubicek, P. Logistics land use patterns in metropolitan Canada. J. Transp. Geogr. 2019. [CrossRef]

50. Xie, S.H.; Cai, H.Y. Research on logistics linkage and logistics network optimization of Yangtze River Delta city group. Geogr. Geogr. Inf. Sci. 2015, 31, 76-82.

51. Ding, J.; Wang, K.Y. Spatial pattern, morphological characteristics and influencing factors of industrial production in urban agglomerations of the Pearl River Delta. Prog. Geogr. Sci. 2016, 35, 610-621.

52. Ma, Y.; Ji, Q. Spatial linkage analysis of the impact of regional economic activities on PM 2.5 pollution in China. J. Clean. Prod. 2016, 139, 1157-1167. [CrossRef]

53. Liang, H.W.; Dong, L. Balancing regional industrial development: Analysis on regional disparity of China's industrial emissions and policy implications. J. Clean. Prod. 2016, 126, 223-235. [CrossRef]

54. Zhao, B.S.; Zhang, J.L. Impact of Time Restriction and Logistics Sprawl on Urban Freight and Environment: The Case of Beijing Agricultural Freight. Sustainability 2019, 11, 3675. [CrossRef]

55. Ye, C.H.; Sun, C.W. New evidence for the impact of financial agglomeration on urbanization from a spatial econometrics analysis. J. Clean. Prod. 2018, 200, 65-73. [CrossRef] 